\title{
ANNOTATIONS
}

\section{Eyestrain in Cinemas}

The interim report of the joint committee appointed by the Illuminating . Engineering Society last year, recently published in the journal of that Society, is noteworthy in that it is the result of investigations by a committee composed of representatives of Engineering, Ophthalmology, Physiology, the London County Council (Public Health, Education, and Fire Departments), and the Cinema Industry.

The recommendations contained in the report (see p. 482) are the result of critical examination of the conditions actually existing in cinema halls in London visited by members of the committee. The point to which attention has been primarily directed is the angle of elevation of the screen seen from seats in the front part of the hall.

It has for long been recognized that eyeache and headache are frequently induced by prolonged observation of pictures and other objects at a level much above that of the observer. Hence the proximity of seats to the screen and the height of the screen are matters of importance. The Committee's judgment that the angle of elevation should not exceed $35^{\circ}$, is one that entails no practical difficulties and one which it is to be hoped will be made obligatory in halls in which, at the present time, this condition does not obtain.

The practical and common-sense recommendations and suggestions of the Committee deserve, and, we trust, will obtain the careful consideration of those concerned in the construction and lighting of new cinema theatres.

The result of the further labours of the Committee will be awaited with interest.

\section{"Suspended Journals"}

There is an element of sly malice underlying an editorial dealing with "suspended journals," recently published by the American Journal of Ophthalmology. From the note by our contemporary it appears that in its issue of May-June, 1918, the Centralblatt $f$. praktische Augenheilkunde, referring to the consolidation of ophthalmic journals that had taken place during the war, rehearsed with evident pride the list of seven German periodicals devoted to ophthalmology, of which all were in existence. The Centralblatt itself, however, ceased publication with the issue of the December, 